AL-MARSHAD: JURNAL ASTRONOMI ISLAM DAN ILMU-ILMU BERKAITAN

ISSN 2442-5729 (print) || ISSN 2598-2559 (online), http://jurnal.umsu.ac.id/index.php/almarshad DOI: https://doi.org/10.30596/jam.v4i2.2480

Published December 2018

\title{
Teks dan Konteks Ayat-Ayat Hisab Muhammadiyah
}

\author{
Muhammad Rifqi Arriza \\ DPS BMT Fastabiq Khoiro Ummah, Pati, Jawa Tengah \\ Email: rifqiarriza@gmail.com
}

\begin{tabular}{|c|c|}
\hline Abstract & Artikel Info \\
\hline $\begin{array}{l}\text { The fact that the Koran is a divine word, has always been a } \\
\text { magnet in itself for Muslims to always explore God's } \\
\text { guidance in it. Scholars and scientists from various } \\
\text { disciplines in every age have read it from various aspects. } \\
\text { However, the Koran always proves that he will not be } \\
\text { discussed by humans, not bound by place and time. One } \\
\text { feature of reading the Koran is the interpretation approach. } \\
\text { Interpretation itself has many features, ranging from } \\
\text { analytical, thematic interpretations, seen from the aspects of } \\
\text { fiqh, language, science, and so on. }\end{array}$ & $\begin{array}{c}\text { Received: } \\
13 \text { September } 2018 \\
\text { Revised: } \\
16 \text { Oktober } 2018 \\
\text { Accepted: } \\
23 \text { November } 2018\end{array}$ \\
\hline $\begin{array}{l}\text { Keyword: Text, Context, Verses of Reckoning, } \\
\text { Muhammadiyah. }\end{array}$ & \\
\hline \multicolumn{2}{|l|}{ Abstrak } \\
\hline $\begin{array}{l}\text { Alquran pada dasarnya adalah kata ilahi, yang selalu } \\
\text { menjadi magnet tersendiri bagi umat Islam untuk selalu } \\
\text { mengeksplorasi tuntunan Tuhan di dalamnya. Para } \\
\text { cendekiawan dan ilmuwan dari berbagai disiplin ilmu di } \\
\text { setiap zaman telah membacanya dari berbagai aspek. } \\
\text { Namun, Alquran selalu membuktikan bahwa ia tidak akan } \\
\text { dibicarakan oleh manusia, tidak terikat oleh tempat dan } \\
\text { waktu. Salah satu fitur membaca Alquran adalah pendekatan } \\
\text { interpretasi. Interpretasi itu sendiri memiliki banyak fitur, } \\
\text { mulai dari interpretasi tematik, analitis, dilihat dari aspek } \\
\text { fikih, bahasa, sains, dan sebagainya. }\end{array}$ & \\
\hline $\begin{array}{l}\text { Kata Kunci: Teks, Konteks, Ayat-Angka Retak, } \\
\text { Muhammadiyah. }\end{array}$ & \\
\hline
\end{tabular}

\section{A. Pendahuluan}

Fakta bahwa al-Quran adalah kalam ilahi, selalu menjadi magnet tersendiri bagi umat Islam untuk selalu menggali petunjuk Tuhan yang ada di dalamnya. Para ulama maupun ilmuwan dari berbagai disiplin ilmu di setiap zaman telah membacanya dari berbagi aspek. Walaupun begitu, al-Quran selalu membuktikan diri bahwa ia tidak akan habis dibahas manusia, tidak terikat oleh tempat dan waktu. 
AL-MARSHAD: JURNAL ASTRONOMI ISLAM DAN ILMU-ILMU BERKAITAN

ISSN 2442-5729 (print) || ISSN 2598-2559 (online), http://jurnal.umsu.ac.id/index.php/almarshad DOI: https://doi.org/10.30596/jam.v4i2.2480

Published December 2018

ولا تنقضي Rasulullah Saw. pun bersabda; عجائبـه al-Quran tidak akan habis keajaibannya. $^{1} \quad$ Sesuatu yang membuktikan bahwa ia adalah murni firman Tuhan, tak ada satu makhluk pun yang dapat menandinginya.

Salah satu corak pembacaan alQuran adalah dengan pendekatan tafsir. Tafsir sendiri mempunyai banyak corak, mulai dari tafsir analitis, tematis, dilihat dari aspek fikih, bahasa, sains, dan sebagainya. Mufasir dari setiap corak ini akan mencoba memahami teks alQuran dari disiplin ilmu yang digelutinya. Hal ini juga berangkat dari paradigma yang dilandasi sabda Nabi; al-Quran mengandung pemahaman yang beragam. ${ }^{2}$

Pada makalah yang sederhana ini, penulis akan mencoba mengupas metode yang ideal dalam tafsîr 'ilmy, serta contoh aplikasinya. Tulisan ini juga akan membahas metode tafsir Muhammadiyah dalam memahami ayatayat hisab.

\section{B. Definisi}

\footnotetext{
${ }^{1}$ HR. Tirmidzi dan al-Darimi.

${ }^{2}$ Riwayat Ibnu Saad dari Ibnu Abbas. Lihat: Jalaluddin Abdur Rahman al-Suyuti, alItqân fì 'Ulûmi'l Qur'ân, (Wazarah al-Syuun alIslamiyah wa al-Awqaf wa al-Dakwah wa alIrsyad, tt, juz 3), h. 977.
}

Dalam bahasa, Tafsir adalah bentuk taf'îl dari al-Fasru, yang berarti kejelasan, keterbukaan, dan memperlihatkan makna yang dapat dipahami ${ }^{3}$. Adapun dalam istilah, banyak sekali ulama yang mencoba mendefinisikannya, sehingga ada puluhan varian definisi yang mereka tawarkan. Singkatnya, menurut hemat penulis, definisi yang ditawarkan oleh imam Zurqani adalah definisi yang paling dapat mewakili kegiatan penafsiran al-Quran, yaitu ilmu yang membahas al-Quran untuk memahami maksud Allah Swt. dengan segenap kemampuan manusia. ${ }^{4}$

Ilmu menurut bangsa Arab adalah pengetahuan yang benar tentang hakekat sesuatu. Sedangkan ilmu yang dimaksud dari kata tafsîr 'ilmy adalah ilmu pengetahuan dan hasil riset yang membahas tentang alam dan kehidupan. ${ }^{5}$

\footnotetext{
${ }^{3}$ Manna' Qatthan, Mabâhits fì 'Ulumui'l Qurân, (Kairo:Maktabah Wahbah, cet. XIII, 2004), h. 316.

${ }^{4}$ Versi Arabnya; علم يبحث فيـه عن أحوال القرآن الكريم من حيث دلالته عاى مراد الله تعالى بقدر الطاقة البشرية. Lihat: Muhammad Abdul Azhim alZarqani, Manâhilu'l 'Irfân fî 'Ulûmi'l Qurân, Kairo: Dar el-Hadits, cet I, 2001, juz 2), h. 7.

${ }^{5}$ al-Mausû'ah al-Qurâniyyah alMutakhashishah,( Kairo: Al-Majlis al-A'la li alSyuun al-Islamiyah, cet I, 2009), h. 692.
} 


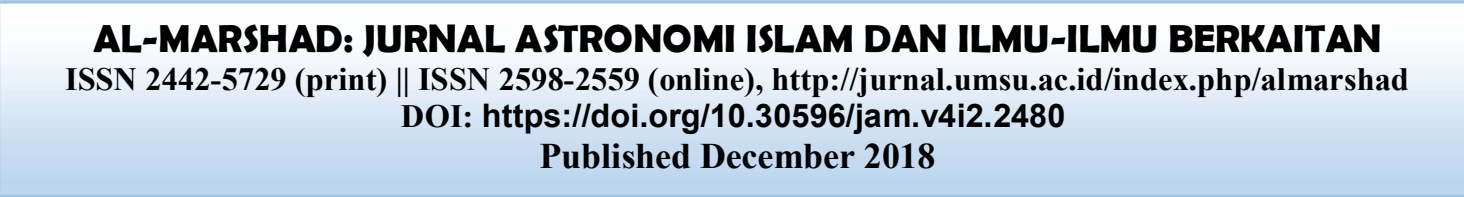

Maka tafsîr 'ilmy adalah

memahami makna baru dari ayat-ayat al-Quran berdasarkan teori-teori pengetahuan yang teruji kebenarannya tentang alam. ${ }^{6}$ Patut diketahui, bahwa tafsîr 'ilmy dan i'jâz 'ilmy tidaklah sama, i'jâz 'ilmy adalah konfirmasi keterdahuluan al-Quran dalam menunjukkan suatu hakekat tentang alam sebelum ditemukan oleh para ilmuan, ribuan tahun setelah masa pewahyuan. ${ }^{7}$

\section{c. Sikap Ulama terhadap Tafsir 'Ilmy}

Dr. Zaghlul Najar menyebutkan, setidaknya ada tiga kelompok ulama dalam menyikapi munculnya corak tafsîr 'ilmy ini.

1. Menentang adanya tafsîr 'ilmy.

Mereka berpendapat bahwa tafsîr 'ilmy ini termasuk tafsir bi al-ra'yi al-madzmûm, tafsir dengan akal yang tercela. Cukup banyak ulama yang memegang pendapat ini, dari ulama terdahulu ada imam Syathibi yang masyhur dengan Muwâfaqât-nya. Adapun dari kontemporer, ada Mahmud

\footnotetext{
${ }^{6}$ Ibid, h. 694.

${ }^{7}$ Zaghlul Raghib Muhammad al-Najar, Madkhal ilâ Dirâsati'l I'jâz al-'Ilmy fì'l Qurâni'l Karîm wa al-Sunnah al-Nabawiyyah, (Beirut: Dar el-Ma'rifah, cet I, 2009), h. 131.
}

Syaltut, Sayid Qutb, Amin Khuli, Musthafa al-Maraghi, Abdul Halim Mahmud, Manna' Qattan, ${ }^{8}$ dan lainnya. ${ }^{9}$ Pendapat mereka berlandaskan Sabda Nabi Saw.; من قال فى القرآن برأيه فأصاب فقاب أخطأ 10 dan dalil-dalil serupa lainnya. ${ }^{11}$

2. Menganjurkan adanya tafsîr 'ilmy.

Karena al-Quran tidak akan habis keajaibannya. Mereka bahkan mengatakan bahwa semua ilmu pengetahuan bersumber dari al-Quran. Seperti imam Ghazali, beliau menguatkan pendapatnya ini dengan perkataan Ibnu Mas'ud ra.; barang siapa yang ingin menguasai ilmu orang terdahulu dan yang akan datang, maka hendaklah dia mentadabburi al-Quran. ${ }^{12}$ Ulama lain yang mendukung imam Ghazali adalah imam Suyuti dan Ibnu Abi al-Fadhl al-Mursi.

3. Sikap tengah.

Bahwa menggunakan tafsîr 'ilmy dalam memahami al-Quran adalah boleh dengan beberapa syarat yang ketat. Termasuk mereka yang

\footnotetext{
${ }^{8}$ Ibid, h. 267.

${ }^{9}$ Yusuf al-Qaradhawi, Kaifa Nata'âmalu ma'al Qurâni'l 'Azhim, (Kairo: Dar el-Syuruq, cet. V, 2006), h. 371.

${ }^{10}$ HR. Tirmidzi dan Abu Daud.

${ }^{11}$ Ibid, h. 81.

${ }^{12}$ Yusuf al-Qaradhawi, Kaifa Nata'âmalu ma'al Qurâni'l 'Azhim, h. 374.
} 
AL-MARSHAD: JURNAL ASTRONOMI ISLAM DAN ILMU-ILMU BERKAITAN

ISSN 2442-5729 (print) || ISSN 2598-2559 (online), http://jurnal.umsu.ac.id/index.php/almarshad DOI: https://doi.org/10.30596/jam.v4i2.2480

Published December 2018

memegang pendapat ini adalah Yusuf al-Qaradhawi dan Dr. Zaghlul Najar. Landasan mereka adalah:

a) Kebutuhan untuk mengetahui pengetahuan mendasar tentang teori alam.

b) Cakupan pengetahuan seorang spesialis lebih dari orang lain. ${ }^{13}$

c) Himbauan Allah Swt. kepada manusia untuk melihat alam dan fenomenanya.

d) Larangan untuk melakukan taklid kepada pendapat terdahulu, serta menghukumi dengan perkiraan dan hawa nafsu. ${ }^{14}$

e) Kebenaran al-Quran dalam setiap ayatnya, yang mencakup ilmu pengetahuan, dapat menarik non muslim untuk memeluk Islam.

\section{Syarat-Syarat Diterimanya Tafsîr}

\section{'Ilmy}

1. Mengedapankan teori-teori yang telah teruji, bukan sebaliknya.

2. Menjauhi penafsiran yang terlalu dipaksakan dalam memahami suatu ayat.

${ }^{13}$ Ibid, h. 379.

${ }^{14}$ Zaghlul Raghib Muhammad al-Najar, Madkhal ilâ Dirâsati'l I'jâz al-'Ilmy fíl Qurâni'l Karîm wa al-Sunnah al-Nabawiyyah, h. 122.
3. Tidak mengklaim ketidaktahuan seluruh umat terhadap wacana keilmuan yang akan kita angkat dari suatu ayat. ${ }^{15}$

4. Memperhatikan prosedur penafsiran secara umum.

5. Berusaha tidak masuk ke dalam pembahasan teori-teori yang rumit, kecuali jika benar-benar dibutuhkan.

6. Tidak membahas hal-hal yang gaib.

7. Memperhatikan konteks ayat.

8. Mengakui relativitas penafsiran, dan tidak mengklaim bahwa tafsirnya adalah paling benar.

9. Meyakini kebenaran semua ayat al-Quran, dalam lafal dan maknanya. ${ }^{16}$

10. Memperhatikan pendapat para mufassir terdahulu. ${ }^{17}$

\section{E. Tafsir Ayat Hisab Muhammadiyah}

Dalam lingkup Muhammadiyah, metode hisab baru dianggap sama kedudukannya dengan rukyat pada tahun

${ }^{15}$ Yusuf al-Qaradhawi, Kaifa Nata'âmalu ma'al Qurâni'l 'Azhim, h. 382.

${ }^{16}$ Zaghlul Raghib Muhammad al-Najar, Madkhal ilâ Dirâsati'l I'jâz al-'Ilmy fî'l Qurâni'l Karîm wa al-Sunnah al-Nabawiyyah, h. 150152.

${ }^{17}$ Abdul Ghafur Mahmud Musthafa Ja'far, al-Tafsîr wa'l Mufassirîn fî Tsaubihi'l Jadîd, (Kairo: Dar el-Salam, cet I, 2007), h. 793. 
AL-MARSHAD: JURNAL ASTRONOMI ISLAM DAN ILMU-ILMU BERKAITAN

ISSN 2442-5729 (print) || ISSN 2598-2559 (online), http://jurnal.umsu.ac.id/index.php/almarshad DOI: https://doi.org/10.30596/jam.v4i2.2480

Published December 2018

2003 (HPT XXVI, 2003). Dalam mengambil pendapat ini, Muhammadiyah mengambil landasan dari al-Quran, sunnah, fikih, dan keakuratan hasil perhitungan hisab.

Penulis akan mencoba membahas ayat-ayat yang menjadi landasan Muhammadiyah dalam mengedepankan hisab daripada rukyat. Setidaknya ada empat ayat yang melandasi pilihan tarjih Muhammadiyah, yaitu:

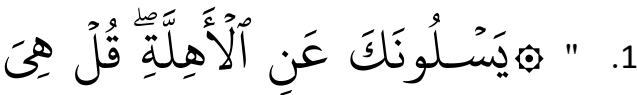

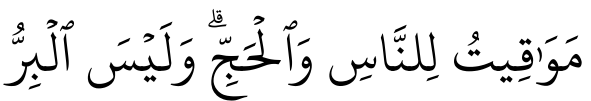
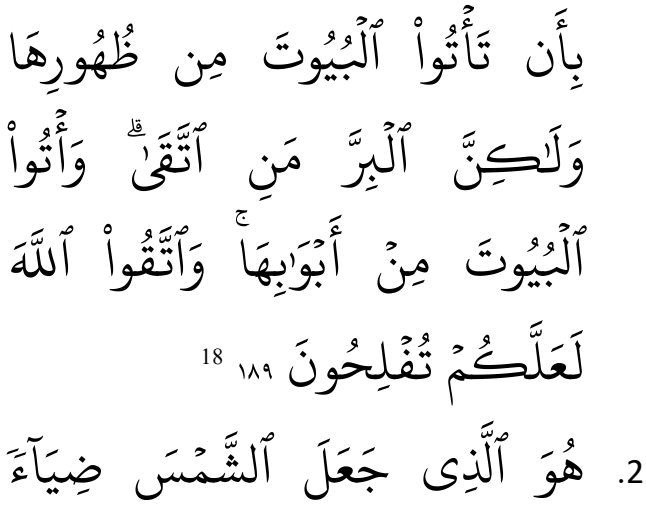

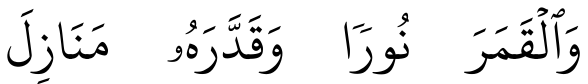
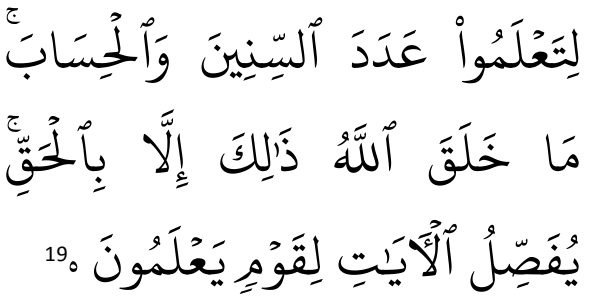

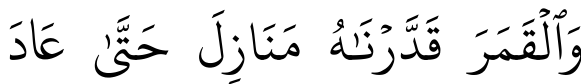

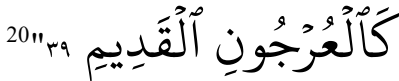

\footnotetext{
${ }^{18}$ QS. al-Baqarah: 189

${ }^{19}$ QS. Yunus: 5.

${ }^{20}$ QS. Yasin: 39-40.
}

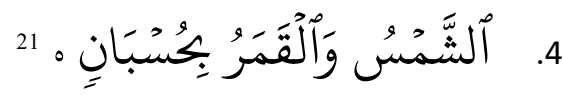

Muhammadiyah memahami empat ayat diatas dengan beberapa pendekatan;

1. Sesuatu yang mempunyai orbit tentu dapat dihitung dengan tepat.

2. Bentuk lafal yang informatif tidak menafikan spirit penggunaan hisab, bahkan hal itu berubah menjadi bentuk imperatif yang memerintahkan untuk mempelajari gerak benda-benda langit, untuk menyusun sistem waktu yang baik (sebagaimana disampaikan dalam al-Baqarah ayat 189 dan Yunus ayat 5), sekaligus meresapi keagungan Allah Swt.. ${ }^{22}$

Muhammadiyah kemudian menjadikan ayat $39 \& 40$ dari surat Yasin sebagai kriteria awal bulan, biasa disebut dengan kriteria "Wujudul Hilal". Walaupun tidak menafikan perangkat ilmu lainnya dalam memutuskan kriteria ini. Ada tiga hal yang menjadi kriteria Wujudul Hilal ini, yaitu;

\footnotetext{
${ }^{21}$ QS. al-Rahman: 5.

${ }^{22}$ Pedoman Hisab Muhammadiyah, (Yogyakarta, Majelis Tarjih dan Tajdid Muhammadiyah, cet II, 2009), h. 75.
} 
AL-MARSHAD: JURNAL ASTRONOMI ISLAM DAN ILMU-ILMU BERKAITAN

ISSN 2442-5729 (print) || ISSN 2598-2559 (online), http://jurnal.umsu.ac.id/index.php/almarshad DOI: https://doi.org/10.30596/jam.v4i2.2480

Published December 2018

a) Telah terjadi ijtimak (konjungsi).

b) Konjungsi terjadi sebelum terbenamnya matahari.

c) Bulan berada diatas ufuk pada saat terbenamnya matahari. ${ }^{23}$

Kriteria (a) terinspirasi dari ayat manzilah-manzilah bulan, sedangkan kriteria (b) dan (c) diambil dari konsep hari dalam kaitannya dengan siang dan malam.

Selanjutnya, penulis akan mencoba memaparkan penjelasan para mufassir terkait empat ayat diatas;

1) Al-Baqarah: 189.

Ibnu Katsir dan al-Razi menulis, ayat ini menjelaskan bahwa pergerakan bulan dapat menjadi ukuran waktu bagi kebutuhan agama maupun dunia. ${ }^{24}$ Yang menarik adalah bahwa mereka sama sekali tidak menyinggung metode hisab, bahkan Ibnu Katsir memberikan riwayat sebab turunnya ayat ini, yang notabene adalah salah satu dalil penggunaan rukyat dalam penentuan awal bulan kamariah.

"عن ابن عمر قال: قال رسول الله صلى الله عليه و

سلم: جعل الله الأهلة مواقيت للناس فصوموا لروئه

${ }^{23}$ Ibid, h. 78-82.

${ }^{24}$ Ismail bin Katsir, al-Tafsîr al-Qurân al'Adzîm, Kairo: Maktabah Shafa, cet I, 2004), h. 266.

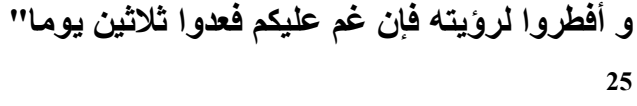

Adapun imam Qurtubi, beliau meriwayatkan hadis yang kontraproduktif dengan pemakaian hisab. Bahwa besar-kecilnya bulan tidak menjadi ukuran penanggalan, tapi hal itu dilihat dari kapan seseorang melihat awal bulan.

"روى المسلم عن أبى البختري قال: خرجنا للعمرة

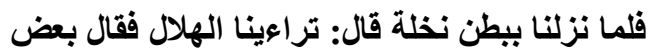
القوم: هو ابن ثُلاث، وقال بعض القوم: هو ابن ليلتين. قال: فلقينا ابن عباس فقلنا: إنا رأينا الهلال فقال بعض القوم: هو ابن ثلاث، وقال بعض القوم: هو ابن ليلتين. فقال: أي ليلة رأيتموه؟ قال فقلنا: ليلة كذا و كذا. فقال إن رسول الله صلى الله عليه و سلم قال: إن الله مده للروئة".26

Sedangkan imam al-Razi, beliau menjelaskan pengertian dari semua ukuran waktu; tahun, bulan, hari, dan jam. Beliau menerangkan bahwa bulan adalah sebuah istilah untuk gerakan bulan dari titik tertentu di orbitnya untuk kembali kepada titik tersebut. ${ }^{27}$ Yang menarik adalah bahwa al-Razi

${ }^{25}$ Muhammad Nashirudin al-Albani, Shahîh al-Jâmi' al-Shaghîr wa Ziyâdâtuhu, (Beirut: al-Maktab al-Islami, cet III, 1988), h. 594.

${ }^{26}$ Muhammad bin Ahmad al-Anshari alQurtubi, al-Jâmi' li Ahkâmi'l Qurân, (Kairo: Maktabah Tawfikia, tt), h. 310.

${ }^{27}$ Ibid, h. 110. 
AL-MARSHAD: JURNAL ASTRONOMI ISLAM DAN ILMU-ILMU BERKAITAN

ISSN 2442-5729 (print) || ISSN 2598-2559 (online), http://jurnal.umsu.ac.id/index.php/almarshad DOI: https://doi.org/10.30596/jam.v4i2.2480

Published December 2018 hanya berhenti pada kata "titik tertentu", tanpa memberikan ukuran yang jelas.

2) Yunus: 5

Dalam ayat ini, ketiga mufassir berhenti pada tafsir normatif, tafsîr bi'l $m a ' t s \hat{u}$. Hanya imam Qurtubi yang lumayan berani memberikan penjelasan lanjut tentang ayat ini, tapi beliau pun masih berkutat dalam koridor manthûq, bahwa bulan mempunyai 28 manzilah, dan dua hari untuk nuqshân dan mahâq (konjungsi). ${ }^{28}$

3) Yasin: 39-40.

Ibnu Katsir menyebutkan pendapat Hasan Bashri, bahwa ayat adalah malam dimana hilal pertama kali dilihat, awal bulan kamariah. ${ }^{29}$ Sedangkan al-Razi dan Qurtubi hanya membahasnya dari sisi manth $\hat{u} q$ kedua ayat ini, tidak ada hal baru dari sisi ilmu pengetahuan tentang bulan. walaupun begitu, imam Qurtubi memberikan nama-nama dari setiap manzilah bulan yang 28 dalam tafsirnya. ${ }^{30}$

4) Al-Rahman: 5 .

${ }^{28}$ Yusuf al-Qaradhawi, Kaifa Nata'âmalu ma'al Qurâni'l 'Azhim, h. 267

${ }^{29}$ Ismail bin Katsir, al-Tafsîr al-Qurân al'Adzîm, h. 291.

${ }^{30}$ Muhammad bin Ahmad al-Anshari alQurtubi, al-Jâmi' li A hkkâmi'l Qurân, h. 25.
Tidak banyak tambahan baru dari ketiga mufassir dalam penafsiran ayat ini.

\section{F. Epilog}

Perlu diakui, bahwa penafsiran Muhammadiyah dalam ayat-ayat hisabnya tidak didukung oleh penafsiran para mufassir terdahulu. Tapi hal ini dapat terkaver dengan paradigma bahwa zaman kita beda dengan mereka, sehingga pemahaman terhadap teks pun berbeda, mengikuti perkembangan zaman.

Penulis sendiri setuju dengan pemakaian hisab yang proporsional yang mengakomodir rukyat dalam penentuan awal bulan kamariah. Dalam hal ini, Dar el-Ifta Mesir bisa jadi contoh ideal dalam keselarasan pemakaian hisab dan rukyat. Wallahu A'lam[]

\section{Daftar Pustaka}

al-Suyuti, Jalaluddin Abdur Rahman. (tt) al-Itqân fì 'Ulûmi'l Qur'ân, Wazarah al-Syuun al-Islamiyah wa al-Awqaf wa al-Dakwah wa al-Irsyad. 
AL-MARSHAD: JURNAL ASTRONOMI ISLAM DAN ILMU-ILMU BERKAITAN

ISSN 2442-5729 (print) || ISSN 2598-2559 (online), http://jurnal.umsu.ac.id/index.php/almarshad DOI: https://doi.org/10.30596/jam.v4i2.2480

Published December 2018

Qatthan, Manna'. (2009). Mabâhits fî

'Ulumui'l Qurân. Kairo:

Maktabah Wahbah.

al-Zarqani, Muhammad Abdul Azhim.

(2001). Manâhilu'l 'Irfân fî

'Ulûmi'l Qurân. Kairo: Dar el-

Hadits.

al-Mausû́'ah al-Qurâniyyah al-

Mutakhashishah. (2009). Al-

Majlis al-A'la li al-Syuun al-

Islamiyah. Kairo: Al-Majlis al-

A'la li al-Syuun al-Islamiyah.

al-Najar, Zaghlul Raghib Muhammad.

(2009) Madkhal ilâ Dirâsati'l I'jâz

al-'Ilmy fî'l Qurâni'l Karîm wa al-

Sunnah al-Nabawiyyah. Beirut:

Dar el-Ma'rifah.

al-Qaradhawi, Yusuf. (2006). Kaifa

Nata'âmalu ma'al Qurâni'l

'Azhim. Kairo: Dar el- Syuruq.

Ja'far, Abdul Ghafur Mahmud

Musthafa. (2007). al-Tafsîr wa'l

Mufassirîn fî Tsaubihi'l Jadîd.

Kairo: Dar el-Salam.

Pedoman Hisab Muhammadiyah.

(2009). Majelis Tarjih dan Tajdid

Muhammadiyah, Yogyakarta:

Pedoman Hisab Muhammadiyah.

Ibn Katsir, Ismail. (2003). al-Tafsîr al-

Qurân al-'Adzîm. Kairo:

Maktabah Shafa.
al-Albani, Muhammad Nashirudin.

(1988). Shahîh al-Jâmi' al-

Shaghîr wa Ziyâdâtuhu, Beirut:

al-Maktab al-Islami.

al-Qurtubi, Muhammad bin Ahmad al-

Anshari. (tt) al-Jâmi' li Ahkâmi'l

Qurân, Kairo: Maktabah

Tawfikia. 